\title{
DERECHOS HUMANOS Y PUEBLO MAPUCHE
}

\author{
Soledad Molinet ${ }^{92}$ \\ Cristián Peralta ${ }^{93}$
}

\begin{abstract}
Son muchas las interrogantes que tengo, ¿por qué nuevamente el Estado me acusa de algo que no he cometido? Nunca me imaginé vivir un segundo allanamiento, de noche, transgrediendo mi espacio sagrado y rompiendo nuevamente mi equilibrio. ¿Por qué se quiere dañar la imagen de una MACHI? Me gustaría explicarle mi rol: yo no elegí ser $M A C H I$, sino que es una función que llegó a mí y debí asumir, es un trabajo al servicio de los demás con

la finalidad de devolver la salud física, espiritual y guiar en el proceso de ser persona en el mundo mapuche. Como le contaba la vez anterior, vivo con mi hermana, una sobrina que es como nuestra hija y su pequeña hijita Paula; somos mujeres que hemos salido adelante gracias al trabajo, esfuerzo y también a la dignidad de nuestro Pueblo. Por ellonomerezcosercondenada públicamente sin una investigación seria y un juicio justo, en realidad no debo pasar por dicho proceso, pues soy inocente. La otra vez le escribí para contar sobre las diversas gestiones que he realizado para lograr vivir plenamente, en mi territorio, ejerciendo mi rol tradicional, lo cual busco desdeel año 2008, donde lucho por acceder a un sitio de significancia cultural y donde recolecto mi LAWEN (plantas medicinales), espacio al cual aún no puedo acceder libremente, pero que se constituye en el primer recurso de protección donde se utiliza el Convenio 169 de la OIT, y que me hace conocida a nivel nacional e internacional. MACHI Francisca Linconao Extracto carta abierta a Michelle Bachelet, Lof Rahue, abril, 2016
\end{abstract}

\section{La urgente necesidad de comprender, respetar y promover los derechos humanos}

Desde octubre del año recién pasado (2019) nuestra sociedad se vio, lamentablemente, obligada a hablar cotidianamente de las graves violaciones a los derechos humanos que ocurrían, incluyendo muertes a manos de agentes del Estado. Se hizo urgente el rechazo generalizado de las masivas y sistemáticas violaciones que ocurrían a nivel nacional, lo que trajo a la memoria los terribles actos de atropello a los derechos humanos durante la dictadura cívico militar que inició en 1973.

Sobre la noción de derechos humanos no encontraremos una única definición, por ejemplo, Naciones Unidas señala: "Los derechos humanos son derechos inherentes a todos los seres humanos, sin distinción alguna de raza, sexo, nacionalidad, origen étnico, lengua, religión o cualquier otra condición" (ONU, 1948: 12). Por otro lado, el Instituto Nacional de Derechos Humanos (INDH), en sus inicios, lo define como: "Las expresiones de derechos humanos y derechos fundamentales indistintamente se refieren a las facultades que tienen las personas, por

\footnotetext{
92 Universidad Alberto Hurtado smolinet@indh.cl

${ }^{93}$ Universidad Católica de Temuco cperaltacelis@gmail.com
} 


\section{Capitulo 4. Página 2}

una parte, para vivir libres de la intervención arbitraria del Estado, y por otra, para solicitar al Estado que realice determinadas acciones destinadas a permitirles desenvolverse en sus vidas" (INDH, 2010:16).

En contextos de crisis sociopolíticas se torna central reforzar las características y principios que rigen a los derechos humanos. Dentro de ellas se destaca que son inherentes a las personas (solo por el hecho de ser personas ya tenemos derechos), son indivisibles (es decir no podemos gozar solo de algunos derechos y de otros no) e interdependientes (se relacionan entre sí derechos civiles, políticos, económicos, sociales y culturales) y, por sobre todo, tienen como eje central la dignidad de la persona. Estas características van de la mano con los principios, donde encontramos como eje la igualdad y no discriminación, la participación, ser pro persona y la no regresividad de los derechos.

Los derechos humanos han tenido un desarrollo histórico. Por ejemplo, Squella (2000) reconoce al menos cinco etapas: positivación, generalización, expansión, internacionalización y especificación. En esta última etapa, con la activa movilización de la sociedad civil, se amplió el sujeto de especial protección, apareciendo obligaciones más específicas a los Estados para garantizar los derechos de los niños, niñas y adolescentes, de las mujeres, de los pueblos originarios, de las diversidades sexuales y de las personas mayores, entre otros grupos de especial protección. Esta especialización de derechos no ha estado exenta de debates sobre la primacía de visiones monoculturales o de la occidentalización del desarrollo de los derechos humanos. Todas las movilizaciones e incidencia, tanto en el sistema universal, como americano de derechos humanos, se ha concretado en diversas relatorías ${ }^{94}$ que han ido acogiendo la diversidad y han desarrollado un gran contenido temático sobre las preocupaciones y la agenda de urgencias en derechos humanos. Dada la importancia de este desarrollo, la educación en derechos humanos también es una obligación para los Estados. Existe una declaración específica al respecto ${ }^{95}$, la que debe im- plementarse en todos los niveles de enseñanza, desde pre-básica a la universidad. Una educación efectiva en derechos humanos aportará en que los prejuicios que existen sobre los derechos humanos vayan decayendo, comprendiendo que la misión de la promoción y defensa de los derechos humanos nos compete a todas y todos.

Comisiones especializadas que generan informes con recomendaciones a los Estados, realizan visitas in situ a los países y son un nexo activo con la sociedad civil, entre otras funciones.

Declaración de Naciones Unidas sobre Educación y Formación en Materia de Derechos Humanos (2011), la que en su Art. 2 señala “(...) 1.- La educación y formación en materia de derechos humanos están integradas por el conjunto de actividades educativas y de formación, información, sensibilización y aprendizaje que tienen por objeto promover el respeto universal y efectivo de todos los derechos humanos y las libertades fundamentales, contribuyendo así, entre otras cosas, a la prevención de los abusos y violaciones de los derechos humanos al proporcionar a las personas conocimientos, capacidades y comprensión, y desarrollar sus actitudes y comportamientos para que puedan contribuir a la creación y promoción de una cultura universal de derechos humanos". 


\section{Derechos humanos y casos emblemáticos}

Para el Pueblo Mapuche, ejercer derechos ha representado una lucha constante en el plano institucional y organizacional. Cuando se ha reclamado la autonomía, autodeterminación y recuperación territorial, la respuesta del Estado ha sido la represión policial, tanto en las movilizaciones, allanamientos a los territorios y persecución a autoridades tradicionales. Esta situación ha develado una masiva y sistemática violación de sus derechos de parte del Estado (Pairican, 2014).

El Art. 1 del Pacto de Derechos Económicos, Sociales y Culturales (PIDESC, 1966), señala “(...) Todos los pueblos tienen el derecho de libre determinación. En virtud de ese derecho establecen libremente su condición política y proveen asimismo a su desarrollo económico, social y cultural", y en el Art. 15 a) se reconoce el derecho a "participar en la vida cultural". Han pasado más de 50 años de este importante tratado de derechos humanos, donde se reconocen derechos activos en el ámbito cultural. Chile aún tiene pendiente de ratificación su protocolo facultativo, el cual permite que "las víctimas busquen justicia a nivel internacional por violaciones a sus derechos económicos, sociales y culturales, mediante el envío de comunicaciones individuales al Comité DESC" (ONU, 2010). En el caso del ejercicio de los derechos culturales en los diversos penales donde han permanecido los presos políticos mapuche ${ }^{96}$ se ha develado aún más la actitud racista del Estado, negando el ejercicio de una cultura propia, con valores y tradiciones, que independientemente de la situación procesal de las personas, deben ser garantizados por el Estado.

Nos detendremos en un breve análisis sobre el acceso a la espiritualidad, alimentación y salud tradicional mapuche, reclamaciones permanentes por las personas privadas de libertad mapuche que les ha llevado a realizar movilizaciones radicales, como las huelgas de hambre ${ }^{97}$. Los petitorios de estas huelgas comienzan, por lo general, con una reivindicación política profunda sobre el derecho a la autodeterminación, la recuperación territorial y el rechazo a la aplicación de la Ley Antiterrorista (Le Bonniec, 2014). Luego, algunas invocan las necesi- dades más inmediatas, que se relacionan con mantener su cultura al interior de los penales.

Denominación que se han dado desde fines de la década de 1990 y que busca reivindicar la situación por la cual se encuentran privados de libertad.

97 La huelga de hambre es una medida extrema de reclamación, se llega a ella cuando se agota el diálogo o cuando los acuerdos con la autoridad política no se cumplen. Han sido múltiples las huelgas de hambre desarrolladas por personas mapuche que han marcado el escenario político chileno. Una de las huelgas de hambre históricas fue la que llevó adelante Patricia Troncoso, conocida como "la Chepa", quien a fines del año 2017 y comienzos del 2018, mantuvo por 112 la medida de presión. También está la huelga de la MACHI Francisca Linconao (diciembre 2016) quien, a pesar de haber estado solo 14 días, estuvo en una condición crítica por su estado de salud y espiritual ya muy deteriorado por la prisión preventiva. Ver más antecedentes en: https://radio.uchile.cl/2016/12/31/colegiomedico-sobre-machi-francisca-linconao-aqui-no-con-tamos-con-semanas-contamos-con-dias /

http://www.mapuche.info/news/lanacioncl080130.html, https://radio.uchile. cl/2016/12/31/colegio-medico-sobre-machi-franciscalinconao-aqui-no-contamos-con-semanas-contamos-con-dias/ 
(...) Como es sabido por todos, en estos días me ha tocado asumir nuevamente la prisión política, esta vez aislado y silenciado en el penal CCP-Biobío. Todo producto de la presión política del poder ejecutivo de este Gobierno fascista que no titubea en asumir la defensa de los intereses de los grandes grupos eco- nómicos transnacionales y de las oligarquías criollas, de las que son sus lacayos y representantes. En sus intenciones, además buscan silenciar y deslegitimar nuestras justas demandas históricas de territorio y autonomía, y en mi caso, buscan quebrar mi voluntad de lucha y callar mi voz ${ }^{98}$.

(...) Yo Álvaro Millalen, preso político mapuche en la cárcel de Temuco, comunico a nuestro pueblo y sociedad en general que a partir de hoy martes 19 de febrero de 2019 me sumo a la huelga de hambre líquida que están llevando a cabo los peñi Facundo Jones Huala, Jorge Cayupan y José Cáceres, para exigir derechos intra-pe- nitenciarios de los presos políticos mapuche, como un protocolo de visitas masivas, autorización para realizar ngellipun y taller de cultura mapuche, entre otros ${ }^{99}$.

Las reclamaciones para acceder a la espiritualidad tienen que ver con acceder principal- mente a realizar ceremonias tradicionales como llellipun (rogativa mapuche), celebración WEXIPANTU (inicio de un nuevo ciclo de vida) y MACHITUN (restablecimiento de la salud física y espiritual) (Antona, 2014). Cuando se trata de autoridades tradicionales mapuche, como lonko o machi, la complejidad aumenta, pues ellos/asrequieren de un ejercicio cotidiano para mantener el equilibrio en su salud tanto física como espiritual y que requiere la conexión con su lof o rewe. Sobre la necesidad de ingresar alimentos, esta se encuentra relaciona- da directamente con el ejercicio espiritual, ya que para algunas ceremonias son necesarios determinados alimentos tradicionales (muday, harina tostada, mote), los cuales no se en- cuentran permitidos por Gendarmería, salvo autorización escrita por el jefe/a de cada penal. Tal como lo menciona el Pacto Internacional de Derechos Civiles y Políticos (1966), en su artículo $18.1^{100}$, se debe garantizar el ejercicio a la libertad de culto, ya sea de manera individual o colectiva. El Convenio 169 de la Organización Internacional del Trabajo (OIT), en su Art. 5. a y b, señala la obligación del Estado de reconocer y proteger las prácticas culturales propias de los pueblos indígenas ${ }^{101}$. Sin duda, este es uno de los principales déficits del Estado chileno, ya que cuando se ha autorizado el desarrollo de ceremonias en los penales, han estado condicionadas al cumplimiento de buena conducta, entregadas a través de un beneficio y no de un derecho.

98 Extracto de petitorio huelga de hambre Ramón Llanquileo, año 2013, disponible en: https://www.lemondediplomatique. cl/huelga-dehambre-mapuche.html

99 Extracto de petitorio huelga de hambre Álvaro Millalen, año 2019, disponible en: https://www.mapuexpress. org/2019/02/19/comunicado-publico-alvaro-millalen-preso-politico-mapuche-se-suma-a-huelga-de-hambre-liquida/

100 “(...) Toda persona tiene derecho a la libertad de pensamiento, de conciencia y de religión; este derecho incluye la libertad de tener o de adoptar la religión o las creencias de su elección, así como la libertad de manifestar su religión o sus creencias, individual o colectivamente, tanto en público como en privado, mediante el culto, la celebración de los ritos, las prácticas y la enseñanza".

101 “(...) a) deberán reconocerse y protegerse los valores y prácticas sociales, culturales, religiosas y espirituales propios de dichos pueblos y deberá tomarse debidamente en consideración la índole de los problemas que se les plantean tanto colectiva como individualmente, b) deberá respetarse la integridad de los valores, prácticas e instituciones de esos pueblos. Convenio 169 OIT. 


\section{Capitulo 4. Página 5}

En el ámbito del acceso a la salud tradicional mapuche a personas privadas de libertad, se ha ejercido dicho derecho principalmente por la vía judicial. Así se evidenció con la MACHI Francisca Linconao cuando se encontraba en prisión preventiva (2016) y reclamó en reitera- das ocasiones la necesidad de atención pertinente culturalmente, tanto al interior del Centro Penitenciario Femenino de Temuco, como en el Hospital Intercultural de Nueva Imperial ${ }^{102}$. En Temuco, en julio de 2019, se realizó un encuentro denominado "Nvtram: Las condiciones penitenciarias de la población mapuche. El caso del MACHI Celestino Córdova", donde se cons- tató que con el actual sistema penitenciario los presos mapuche ven constantemente vulne- rado su derecho a la salud, ya que en el penal no hay acceso a médico de manera expedita y el derecho a la atención tradicional mapuche encuentra también múltiples obstáculos ${ }^{103}$. Al respecto, el Convenio 169 de la OIT señala en su Art. 25 “(...) 1. Los gobiernos deberán velar por que se pongan a disposición de los pueblos interesados servicios de salud adecuados...."

Un estudio realizado por el Centro de Estudios Socioculturales de la Universidad Católica de Temuco $(2018)^{104}$, constató una serie de brechas en relación al ejercicio de la cultura en los penales, versus el estándar internacional de derechos humanos. El estudio reconoce buenas prácticas en unos penales más que otros, no obstante, el ejercicio de derechos no debe quedar condicionado a la arbitrariedad, se debe garantizar en todo momento y lugar.

\section{Derechos culturales: una aproximación}

En otra arista de los derechos culturales que afectan al Pueblo Mapuche, en junio del año 2019 el Gobierno ingresó un proyecto de ley sobre patrimonio cultural, en cuyos objetivos se encuentra "modernizar la institucionalidad de la actual Ley de Monumentos Nacionales, actualizar sus categorías y otorgar una protección efectiva al patrimonio cultural de Chile, mediante su identificación, conservación, puesta en valor, gestión y promoción"105. Este proyecto de ley es ampliamente rechazado por múltiples actores como organizaciones de pueblos indígenas, colegio de arqueólogos y artistas, entre otros. Los principales reparos son la nula participación de agentes expertos y la no realización de la Consulta Indígena, tal como lo mandata el Convenio 169 de la OIT. Además, dicha ley no reconoce el patrimonio cultural indígena, ni menos la propiedad intelectual indígena colectiva. Esto representa una grave afectación a los derechos de los pueblos indígenas y contraviene lo recomendado a Chile por el Comité de Derechos Económicos Sociales y Culturales, “(...). El Comité recomienda al Estado parte que a) tome las medidas necesarias para

102 Ver en https://www.biobiochile.cl/noticias/nacional/region-de-la-araucania/2016/11/21/autorizan-que-machi-francisca- linconao-seainternada-en-hospital-intercultural-de-nueva-imperial.shtml

103 Ver en https://radiokurruf.org/2019/07/19/nvtram-las-condiciones-penitenciarias-de-la-poblacion-mapuche-el-caso- del-machicelestino-cordova/

104 Estudio sobre condiciones intra-penitenciarias para imputados y condenados mapuche según estándar de derechos humanos e indígenas vigente en Chile. Temuco, septiembre 2018.

105 Además, la propuesta aborda cuatro áreas: i) centralismo del órgano colegiado, donde, además, se visualiza una estructura orgánica insuficiente y desactualizada; ii) categorías de protección obsoletas y poco eficaces; iii) ausencia de un sistema de compensaciones e incentivos para la conservación, restauración, preservación, puesta en valor y salvaguarda del patrimonio cultural; y iv) delitos e infracciones. Disponible en: https://www.camara.cl/prensa/sala_de_prensa_detalle. aspx?prmid=137320 
fortalecer la protección de los derechos culturales y el respeto a la diversidad cultural, b) promueva la concientización sobre el patrimonio de los pueblos indígenas y c) cree condiciones favorables para que los pueblos indígenas puedan conservar, desarrollar, expresar y difundir su identidad, historia, cultura, lenguas, tradiciones y costumbres..." (DESC, 2015) ${ }^{106}$.

\section{Consulta Indígena}

Entre los meses de abril y junio 2019 se realizó el proceso de Consulta Indígena, desarrollada por el Ministerio de Desarrollo Social y Familia con la finalidad de modificar la Ley Indígena ${ }^{107}$. El proceso de consulta que consideraba cinco etapas ${ }^{108}$, solo logró avanzar en la primera, donde recibió un amplio rechazo a nivel nacional de parte de los nueve pueblos indígenas que habitan el país. El proceso se suspendió el 25 de julio ${ }^{109}$ y luego, en noviembre de 2019, se canceló definitivamente el proceso.

Las críticas desde las organizaciones mapuche se centraron en que el Gobierno impuso un tema que las comunidades no habían requerido, y que se liberalizaba al mercado de tierras la propiedad indígena, beneficiando a las empresas inmobiliarias y forestales más que a las comunidades mapuche. Por otro lado, se visibilizó que el Estado no ha aprendido nada del diálogo con el Pueblo Mapuche, pues no estableció vínculos previos con las autoridades tradicionales y dirigentes territoriales mapuche.

Las dinámicas que establecieron las comunidades mapuche de la Región de La Araucanía para presentar su firme rechazo a la consulta fueron diversas, en algunas reuniones escuchaban la presentación que realizaba el Gobierno, y por medio de los profesionales daban a conocer su rechazo y firmaban las actas requeridas. En otras jornadas comenzaban con una rogativa mapuche, llevaban su propia comida (para no recibir la alimentación proporcionada por el Estado), no se firmaba ningún documento emanado por la institucionalidad y las intervenciones se realizaban mayoritariamente en mapudungun. Lo común fue siempre la indignación al ver que, una vez más, no se respetaba el derecho a la autodeterminación y protección de la propiedad colectiva de la tierra y el territorio mapuche.

\section{Estallido Social y derechos humanos en La Araucanía}

El Estallido Social iniciado el 18 de octubre de 2019, la "revolución de octubre" o la "revuelta popular", implicó un punto de inflexión en la historia nacional post dictatorial, proceso que solo quedó en pausa por la emergencia del COVID-19. En él convergieron diversas subjetividades que expresaban un profundo descontento y malestar. Un “¡basta ya!”, ante un sistema o modelo de vida

\footnotetext{
106 Disponible en https://acnudh.org/24619/

107 Eran once las medidas que se someterían a consulta, las cuales afectaban la propiedad colectiva de las tierras indígenas, acortaba los años de prohibición de venta de la tierra indígena entre personas indígenas, se permitían los contratos de arriendo, comodatos o medierías hasta por 25 años y aumentaban los requisitos para la constitución de comunidades indígenas, entre otras medidas.

108 Planificación, información, deliberación interna, diálogo y sistematización y cierre. 109 Por medio de la Resolución N2ㄴ 241.
} 
implementado — de forma ilegítima- a sangre y fuego, y que se cristalizó, casi treinta años antes, con la Constitución de 1980. Si bien, la Carta Magna fue signada por Ricardo Lagos Escobar y reformada durante la "transición a la democracia", su núcleo o esencia, se mantuvo intacta. La Constitución, como expresión ideológica de sectores antidemocráticos, se constituyó en un traje a la medida (Salazar, 2020) para las élites económicas y la "inversión extranjera", logrando perpetuar un sistema socialmente injusto e insostenible. Primero, debilitando y precarizando lo público y restringiendo o limitando los derechos adquiridos por los movimientos sociales durante gran parte del siglo XX (salud, educación, vivienda, derechos laborales, sistema de pensiones). Y segundo, favoreciendo la concentración de la riqueza, la propiedad y la tierra. En definitiva, un sistema social y político que sigue reproduciendo la desigualdad y cuyos orígenes nos remiten a la Colonia ${ }^{110}$. Además, en este modelo subyace una racionalidad económica de "libre mercado", pero cuyo sustento real se basa principalmente en las actividades de carácter extractivista (minería, agroindustria, industrial forestal, acuícolas, explotación de recursos marítimos), a partir de las concesiones e incentivos estatales a la inversión de privados para la explotación de bienes y activos públicos estratégicos (Código de Aguas, Ley de Pesca y concesiones marítimas, concesiones mineras y DF 70, entre otros).

\footnotetext{
¿Hacia un estado plurinacional? Los usos sociales de la bandera mapuche ¿El ocaso de la "soberanía suspendida"? (Mariman, et AL., 2006). como símbolo de la revolución político-cultural que estaría dando cuenta Fotografía de la estatua de Caupolicán en Temuco con la bandera de un nuevo imaginario de nación. Foto: Susana Hidalgo, "Revolución", mapuche y sosteniendo la cabeza de Dagoberto Godoy. La Plaza Dignidad, Santiago de Chile, 25 de octubre de 2019. simbolización de procesos de descolonización y de la vigencia de la demanda indígena en La Araucanía ${ }^{111}$, reivindicando no solo derechos culturales, sino que derechos político-territoriales.
}
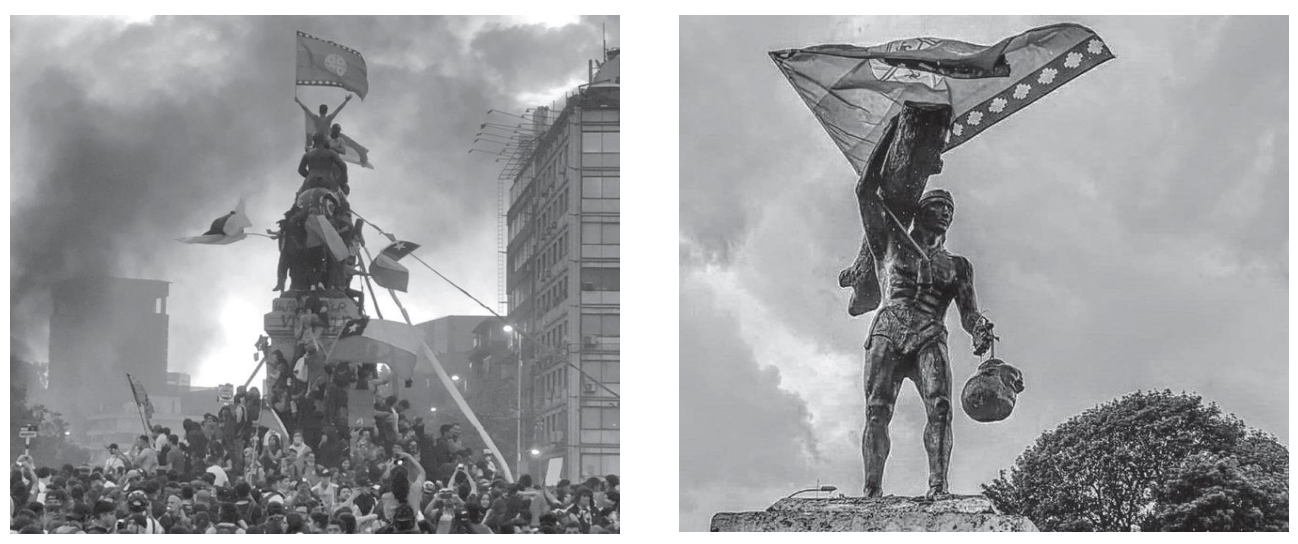

110 Ver capítulo I "La distribución de la riqueza" de la serie documental "La Copia feliz del edén: una mirada a la historia social en Chile 1810-2014" realizada por la Fundación para la Superación de la pobreza y Wood producciones el año 2015.: https://www.youtube.com/watch?v=NwEuYtzvgzM\&list=PLOSKxyGtgoWRqlTqlRMABs9Yk7k24_wBR

111 Ver el artículo publicado en El Desconcierto el 29 de noviembre de 2019 denominado: "Más justicia, menos monumentos": https://www.eldesconcierto.cl/2019/11/29/temuco-mas-justicia-menos-monumentos/ 
La legítima protesta social en Chile fue violentamente reprimida por la acción de la fuerza militar y de las fuerzas del orden. La figura del enemigo interno y la criminalización de la protesta social emergió discursivamente ya en los primeros y célebremente tristes mensajes presidenciales $^{112}$. La clase política y, en particular, el Gobierno, no fueron capaces de hacer un ejercicio reflexivo y menos autocrítico. Por un lado, su respuesta fue el uso de la violencia de Estado a través de la acción militar y policial legitimada a través de la declaración de Estado de Excepción constitucional de emergencia ${ }^{113}$ y, por otro, activó en el Parlamento la incorporación de artilugios jurídicos en el Código Penal para criminalizar la protesta social (ley antiencapuchados) ${ }^{114}$.

Desde octubre del 2019 hasta marzo del 2020, quedó en evidencia que el enemigo interno no era un ser abstracto, sino que tenía cuerpo y rostro de mujer, de jóvenes, de niños y niñas, de estudiantes, de trabajadoras y trabajadores, adultos mayores, inmigrantes, de personas en situación de calle, de los sin casa (campamentos/tomas). Es decir, de miles de ciudadanas y ciudadanos que sueñan —y soñamos— con un país más justo.

\section{Derechos humanos en La Araucanía en el contexto del Estallido}

En el ya friccionado contexto regional de La Araucanía, la activa y pacífica movilización social en los principales centros urbanos de la región, tuvo como contracara la violación sistemática de los derechos humanos a partir de la acción de agentes del Estado, donde la Institución de Carabineros de Chile ha tenido un marcado protagonismo, sin omitir u olvidar acciones de otras instituciones del Estado, algunas de las cuales han tenido una alta connotación pública. Sin duda, uno de los casos de mayor impacto a nivel nacional fue el simulacro de fusilamiento por parte de efectivos militares a dos jóvenes en la ciudad de Temuco en el contexto de Estado de Emergencia ${ }^{115}$.

Según los reportes mensuales del Instituto Nacional de Derechos Humanos de La Araucanía (2020), hasta la primera semana del mes de marzo del presente año se estimaba aproximadamente un total de 440 víctimas de la represión estatal a partir de denuncias canalizadas directamente por el INDH o a través de algunas denuncias derivadas por parte de organizaciones público/privadas, tales como, ABOFEM, Pikete Jurídico, Organismos colaboradores de SENAME, La Defensoría de la Niñez y Brigada Negra, entre otras. De ese universo de personas, el INDH había logrado dar curso a al menos 152 querellas, 53 denuncias individuales, 5 amparos preventivos, 1 amparo de garantía y 1 denuncia colectiva. Estas acciones legales representaban a un total aproximado de 233 personas (183 hombres y 50 mujeres). Estas acciones jurídicas estaban asociadas a delitos atribuidos a agentes del Estado, tales como tortura, amenazas a la libertad, apremios ilegítimos, disparo con perdigón y bombas lacrimógenas al cuerpo y al rostro,

112 Ver Emol 20/10/2019: “Presidente Piñera: Estamos en guerra contra un enemigo poderoso que no respeta a nada ni a nadie". En: https://www.emol.com/noticias/Nacional/2019/10/20/964954/Pinera.html

113 Ver Diario Oficial 19 de octubre del 2019, "Estado de Excepción constitucional de emergencia" https://www.diariooficial. interior.gob.cl/publicaciones/2019/10/19/42481-B/01/1671764.pdf

114 Ver: https://ciperchile.cl/2019/12/26/sobre-la-ley-anti-encapuchados-y-otras-adaptaciones-legales-fascistas/ $115 \quad$ A respecto, ver: https://www.eldesconcierto.cl/2020/02/05/simulacro-de-fusilamiento-en-temuco/ 
y violencia sexual, entre otros. Dentro de las lamentables estadísticas regionales se contabilizaban al menos 12 personas con lesiones oculares y al menos 28 niñas, niños y adolescentes afectados.

Cabe destacar que, según la adscripción étnica, un 20\% de las víctimas asociadas a las acciones legales interpuesta por el INDH eran mapuche, a partir de las denuncias recibidas y canalizadas en el contexto de la movilización social. En estos casos, la mayoría de las víctimas denunciaban no solo maltrato físico, sino que también psicológico a partir de acciones explícitamente discriminatorias, donde los efectivos policiales utilizaban un discurso explícitamente racista, fenómeno que no es casual, sino que responde a un fenómeno de larga data y que da cuenta de una violencia simbólica y material a nivel estructural en La Araucanía (Tricot, 2017; Lepe-Carrión, 2018).

\section{Informes de delegaciones internacionales de derechos humanos}

De la violación masiva y sistemática a los derechos humanos en Chile durante el denominado Estallido Social, dan cuentan tanto los informes de organismos internacionales a partir de misiones y observaciones realizadas en Chile por la Comisión Interamericana de Derechos Humanos (CIDH), Human Rights Watch, Alto Comisionado de Derechos Humanos de Naciones Unidas (ACNUDH) y Amnistía Internacional, así como los diversos reportes emitidos por el propio Instituto Nacional de Derechos Humanos. Uno de los primeros reportes fue el del equipo de crisis de Amnistía Internacional, quienes el 21 de noviembre de 2019 emiten el informe de resultado de la misión. La directora para las Américas, Erika Guevara, destacaba que “(...) la intención de las fuerzas de seguridad chilenas es clara: lesionar a quienes se manifiestan para desincentivar la protesta, incluso llegando al extremo de usar la tortura y violencia sexual en contra de manifestantes"116.

También se hizo presente una delegación de la Oficina del Alto Comisionado de Naciones Unidas para los Derechos Humanos. La delegación visitó las regiones de Antofagasta, Araucanía, Biobío, Coquimbo, Maule, Metropolitana y Valparaíso. En su primer comunicado el equipo declara que “(...) ha revisado alegaciones de uso excesivo de la fuerza por parte de agentes de orden y seguridad en el contexto de protestas; reportes de malos tratos en detención, incluyendo abusos y violencia sexual; alegaciones de vulneraciones a derechos durante la privación de libertad..." ${ }^{117}$. Asimismo, la observación realizada por Human Rights Watch expresa que “(...) hay centenares de preocupantes denuncias sobre uso excesivo de la fuerza en las calles y abusos contra detenidos tales como golpizas brutales y abusos sexuales que no pueden quedar impunes y deben ser pronta y rigurosamente investigadas y sancionadas... Es justamente por ello que las autoridades deben impulsar una reforma policial urgente" ${ }^{118}$. Por su parte, la Comisión Interamericana de Derechos Humanos realizó una visita preparativa a una misión in loco, encabezada por su secretario ejecutivo Paulo Abrão, quien destacó “(...) su grave preocupación por el elevado número

116 Ver en https://www.amnesty.org/es/countries/americas/chile/report-chile/

117 Ver en https://acnudh.org/equipo-onu-derechos-humanos-finalizo-su-visita-a-chile/

118 Verinform e complet o e n t t p s:// w w w.h r w.org/e s/n e w s/2019/11/26/chile-llamadourgente-una-reforma-policial-tras-las-protestas 
de denuncias de graves violaciones a los derechos humanos registrados por distintos organismos internacionales, así como por los propios órganos del Estado"119.

Los puntos comunes en lo planteado por las diversas delegaciones fue el reconocimiento de que en Chile se violaron gravemente los derechos de las personas, que existió un uso desproporcionado de la fuerza que lesionó gravemente a miles de personas, que terminó con la vida de un número aún indeterminado de personas y que el Estado tiene la obligación de investigar y sancionar los distintos hechos, junto con generar acciones de reparación a las víctimas. Al realizar un análisis comparativo, podemos mencionar que el informe más completo es el emitido por Alto Comisionado de Naciones Unidas para los Derechos Humanos (ACNUDH) , donde entrega u marco contextual del origen de la crisis social, producto de las graves desigualdades sociales y económicas, y una mirada desagregada en los grupos de especial protección (mujeres, niños, niñas y adolescentes, defensores de derechos humanos, otros), junto con ofrecer recomendaciones al Estado a la luz del derecho internacional de los derechos humanos. También es destacable que sugiere un seguimiento de la implementación de recomendaciones, junto a organizaciones de la sociedad, en un plazo de tres meses.

El Informe ACNUDH refiere un párrafo especial para la situación del Pueblo Mapuche, donde indica que las autoridades mapuche expresaron que el uso excesivo de fuerza, malos tratos y muertes de sus integrantes han estado presentes cada vez que han reivindicado sus derechos, y que estas situaciones han sido reprochadas al Estado chileno en diversas recomendaciones realizadas por variados comités de derechos humanos, entre ellas el Comité contra la Tortura (2018). Además, se agrega que, según datos del Ministerio Público, son 13 las víctimas del Estallido Social que se han reconocido como indígenas, todas ellas mapuche (ACNUDH, 2019: Párr.117).

Se presenta a continuación un cuadro comparativo para tener a la vista los énfasis de cada misión de observación.

Tabla №1: Cuadro comparativo de informes de misiones de observación a Chile en contexto de crisis de derechos humanos

\begin{tabular}{|l|l|}
\hline HUMAN RIGHTS WATCH \\
\hline Periodo observado & No señala \\
\hline $\mathbf{N}^{\circ}$ entrevistas & 70 víctimas \\
\hline Regiones visitadas & Metropolitana y Valparaíso \\
\hline Principales \\
conclusiones & $\begin{array}{l}\text { Miembros de la policía cometieron graves violaciones de derechos hu- } \\
\text { manos que incluyen uso excesivo de la fuerza en las calles y abusos en } \\
\text { detención, luego de masivas protestas. }\end{array}$ \\
\hline Recomendaciones & $\begin{array}{l}\text { Revisar las facultades de detención por control de identidad de } \\
\text { Carabineros. }\end{array}$ \\
\hline
\end{tabular}




\begin{tabular}{|c|c|}
\hline Recomendaciones & $\begin{array}{l}\text { Asegurar que existan mecanismos internos de control para investigar y } \\
\text { sancionar abusos, y el uso indebido de armas menos letales por parte de } \\
\text { Carabineros. } \\
\text { Reformar el sistema de disciplina de Carabineros. } \\
\text { Adoptar un protocolo junto con las autoridades de salud para que los } \\
\text { detenidos sean sometidos a revisiones forenses independientes, que no se } \\
\text { realicen frente a Carabineros y ocurran a una distancia en la que no } \\
\text { puedan ser escuchados. } \\
\text { Hacer cumplir la prohibición vigente sobre desnudamiento de } \\
\text { detenidos/as en protestas y sancionar a aquellos que continúen con esta } \\
\text { práctica. } \\
\text { Instalar cámaras en todas las áreas de todas las comisarías, tomando } \\
\text { medidas para garantizar la privacidad de los detenidos y establecer un } \\
\text { sistema de almacenamiento de grabaciones que pueda ser empleado por } \\
\text { autoridades judiciales o de otro tipo. } \\
\text { Suspender cualquier uso de perdigones -no solo durante } \\
\text { manifestaciones- hasta que autoridades idóneas e independientes } \\
\text { realicen un estudio adecuado de todos sus riesgos. } \\
\text { Estudiar el uso de equipos menos letales alternativos que minimicen las } \\
\text { lesiones y el entrenamiento de todos los carabineros. } \\
\text { Cerciorarse de que los carabineros cuenten con equipos de protección } \\
\text { adecuados, tiempo de descanso y remuneración de horas extra. }\end{array}$ \\
\hline \multicolumn{2}{|c|}{ AMNISTÍA INTERNACIoNAL } \\
\hline \multicolumn{2}{|c|}{\begin{tabular}{|l|l} 
Periodo observado 19 octubre al 11 noviembre \\
\end{tabular}} \\
\hline $\mathbf{N}^{\circ}$ entrevistas & 23 víctimas \\
\hline Regiones visitadas & $\begin{array}{l}\text { Tarapacá, Antofagasta, Coquimbo, Valparaíso, Metropolitana, El Maule, } \\
\text { Biobío y La Araucanía }\end{array}$ \\
\hline $\begin{array}{l}\text { Principales } \\
\text { conclusiones }\end{array}$ & $\begin{array}{l}\text { La intención de las fuerzas de seguridad chilenas es clara: lesionar a } \\
\text { quienes se manifiestan para desincentivar la protesta, incluso llegando al } \\
\text { extremo de usar la tortura y violencia sexual en contra de manifestantes, } \\
\text { en vez de tomar medidas encaminadas a frenar la gravísima crisis de } \\
\text { derechos humanos. }\end{array}$ \\
\hline Recomendaciones & $\begin{array}{l}\text { Máxima restricción al uso de la fuerza. } \\
\text { Responsabilidad del mando en las violaciones a derechos humanos y } \\
\text { crímenes de derecho internacional cometidos a manos del ejército y la } \\
\text { policía. } \\
\text { Reformas legislativas y de política pública necesarias para garantizar de } \\
\text { forma efectiva los DESC. } \\
\text { Las autoridades deben emprender una reforma seria y profunda de la } \\
\text { policía. }\end{array}$ \\
\hline \multicolumn{2}{|l|}{ ACNUDH } \\
\hline Periodo observado & 18 octubre al 22 noviembre \\
\hline $\mathbf{N}^{\circ}$ entrevistas & 300 integrantes de sociedad civil. 235 entrevistas a víctimas. \\
\hline Regiones visitadas & $\begin{array}{l}\text { Antofagasta, La Araucanía, Biobío, Coquimbo, El Maule, Metropolitana y } \\
\text { Valparaíso. }\end{array}$ \\
\hline
\end{tabular}




\begin{tabular}{|c|c|}
\hline $\begin{array}{l}\text { Principales } \\
\text { conclusiones }\end{array}$ & $\begin{array}{l}\text { Las manifestaciones tienen sus raíces en una multiplicidad de causas, } \\
\text { incluyendo la desigualdad social y económica. } \\
\text { Se ha producido un elevado número de violaciones graves a los derechos } \\
\text { humanos, incluye el uso excesivo o innecesario de la fuerza que resultaron } \\
\text { en la privación arbitraria de la vida, lesiones, torturas, malos tratos, } \\
\text { violencia sexual y detenciones arbitrarias. } \\
\text { Uso innecesario y arbitrario de armas menos letales (gases lacrimógenos, } \\
\text { escopetas antidisturbios) } \\
\text { Graves lesiones oculares. }\end{array}$ \\
\hline Recomendaciones & $\begin{array}{l}\text { Asegurar el derecho a manifestación pacífica. } \\
\text { Asegurar que las fuerzas policiales se apeguen a normas internacionales } \\
\text { sobre el uso de la fuerza. } \\
\text { Poner fin al uso indiscriminado de la escopeta antidisturbios. } \\
\text { Usos de gases lacrimógenos solo de manera excepcional, nunca cerca de } \\
\text { establecimientos de salud y educación. } \\
\text { Impulsar reformas estructurales en Carabineros (supervisión civil, } \\
\text { registros públicos eíntegros, capacitación, entre otros). } \\
\text { Que seguridad ciudadana esté radicada en policía civil. } \\
\text { Asegurar que fuerzas de seguridad rindan cuentas ante violaciones a los } \\
\text { DD.HH. } \\
\text { Asegurar que se cumpla el deber del Estado de investigar todas las } \\
\text { denuncias de violaciones de DD.HH. } \\
\text { Garantizar la responsabilidad penal individual y sanción de altos mandos. } \\
\text { Asegurar que las víctimas tengan acceso a la justicia y reparación. } \\
\text { Recopilar, sistematizar y hacer pública la información sobre violaciones a } \\
\text { los DD.HH. } \\
\text { Fortalecer al SML, Ministerio Público y otros. } \\
\text { Asegurar que todos los detenidos tengan acceso a examinación médica. } \\
\text { Asegurar que los defensores de DD.HH. y comunicadores realicen su } \\
\text { trabajo sin restricciones. } \\
\text { Establecer una instancia de diálogo que identifique causas y } \\
\text { recomendaciones en torno a la crisis social. } \\
\text { Asegurar que el INDH y Defensoría de la Niñez puedan cumplir su } \\
\text { mandato. } \\
\text { Ratificar el protocolo facultativo PIDESC. } \\
\text { Establecer mecanismo de seguimiento con la Oficina Regional } \\
\text { ACNUDH, evaluar dentro de tres meses. }\end{array}$ \\
\hline \multicolumn{2}{|l|}{$\mathrm{CIDH}$} \\
\hline \multicolumn{2}{|c|}{\begin{tabular}{|l|l|} 
Periodo observado 18 octubre al 29 noviembre \\
\end{tabular}} \\
\hline $\mathbf{N}^{\circ}$ entrevistas & $\begin{array}{l}\text { Más de } 100 \text { víctimas, autoridades del Estado, organizaciones de la } \\
\text { sociedad civil y academia. }\end{array}$ \\
\hline Regiones visitadas & Metropolitana y Valparaíso. \\
\hline
\end{tabular}




\begin{tabular}{|c|c|}
\hline $\begin{array}{l}\text { Principales } \\
\text { conclusiones }\end{array}$ & $\begin{array}{l}\text { La CIDH expresa su grave preocupación por el elevado número de } \\
\text { denuncias de graves violaciones a los derechos humanos registrados por } \\
\text { distintos organismos internacionales, así como por los propios órganos del } \\
\text { Estado. Asimismo, expresa su preocupación por las características de } \\
\text { dichas vulneraciones, que apuntarían hacia la existencia de conductas } \\
\text { repetitivas de violencia en contra de manifestantes en el contexto de las } \\
\text { recientes protestas sociales. La CIDH saluda el compromiso anunciado por } \\
\text { el Presidente de la República para que estos casos sean debidamente } \\
\text { investigados, juzgados y sancionados, así como asistir a las víctimas en su } \\
\text { recuperación. }\end{array}$ \\
\hline Recomendaciones & $\begin{array}{l}\text { Llama a que las autoridades ordenen el cese inmediato del uso } \\
\text { desproporcionado de la fuerza por parte de las fuerzas de seguridad del } \\
\text { Estado. } \\
\text { La CIDH recuerda que, de conformidad con los estándares } \\
\text { interamericanos, el mantenimiento del orden público y la seguridad } \\
\text { ciudadana deben estar primordialmente reservados a los cuerpos } \\
\text { policiales civiles. } \\
\text { La CIDH urge a la sociedad chilena a entablar un diálogo efectivo e } \\
\text { inclusivo para abordar las demandas legítimas de la población, con el } \\
\text { máximo respeto a los derechos humanos y en el marco democrático del } \\
\text { Estado de Derecho. En ese sentido, la Comisión saluda los esfuerzos de } \\
\text { convocar a una nueva Constitución. }\end{array}$ \\
\hline
\end{tabular}

Fuente: Elaboración propia.

\section{A modo de conclusión}

El año 2019 sin duda quedará marcado en la historia de Chile por la crisis social y política que estalló en el mes de octubre, pero que tiene sus orígenes en las profundas desigualdades sociales del país. Como respuesta a las manifestaciones, el Estado ofreció una violencia política y policial que nos remontó a los hechos más crueles de la dictadura cívico militar de Augusto Pinochet.

Esta represión a la hora de manifestarse y la indolencia de la política pública que ha vivido el Pueblo Mapuche desde el despojo de su territorio ancestral, se suma a la actitud racista que mantiene el Estado chileno con la aplicación de la legislación antiterrorista a las causas donde se reivindiquen derechos políticos y territoriales. A pesar de develar los montajes ${ }^{120}$ que se han emprendido contra el Pueblo Mapuche, la justicia oficial' y también la pública ha sido esquiva, las condenas sociales son las que han perdurado, el estigma del "mapuche flojo y borracho" ha transitado al "mapuche terrorista e incendiario". Por otro lado, se ha dicho que el Pueblo Mapuche es resiliente, que, a pesar de enfrentar prisión preventiva extensa, juicios por ley antiterrorista, encarcelamiento y luego anulación de juicios, mantienen un profundo sentido de identidad e integridad personal y colectiva, que les hace retomar sus acciones y anhelos políticos de manera decidida (Vargas, 2017). 
La sentencia de la Corte Interamericana del año 2014, en el caso Norin Catriman y otros, ordenó al Estado a anular las condenas de dos lonkos y otros dirigentes, además instruyó que se debían adoptar medidas de reparación a los afectados, junto con adecuar a los estándares internacionales la legislación antiterrorista, entre otras medidas. Pero la mayor esperanza estaba puesta en que el Estado internalizaría el llamado a respetar la presunción de inocencia, el principio de igualdad y no discriminación ante la ley en las causas que se emanan de la reivindicación política y territorial del Pueblo Mapuche.

Los avances en una política indígena digna y pertinente son nulos, la fallida Consulta Indígena por la modificación de la Ley Indígena y la tramitación del proyecto de ley de Patrimonio Cultural, emprendidos el año 2019, así lo demuestran. La política estatal continúa siendo monocultural, racista y clasista. Con todo, en las últimas dos décadas, las y los jóvenes chilenos han dado muestras de que los derechos deben ser para todas y todos, manteniendo en el centro de sus reclamaciones (educación, salud, transporte y otras) la dignidad de las personas. La esperanza está en que ese sentir se amplifique y que el Estado cumpla con su obligación de protección y defensa de los derechos de todos quienes habitamos el país. 


\section{Bibliografía}

AMNISTÍA INTERNACIONAL. (2019) Informe Misión Chile. Disponible en https:// www.amnesty.org/es/countries/americas/chile/report-chile/

ANTONAS, José (2014). Los derechos humanos de los pueblos indígenas. El AZ Mapu y el caso Mapuche. Temuco: Ediciones UCT.

CENTRO DE ESTUDIOS SOCIOCULTURALES (2018) Estudio sobre condiciones intra-penitenciarias para imputados y condenados mapuche según estándar de derechos humanos e indígenas vigentes en Chile. Temuco: Ediciones Universidad Católica de Temuco.

COMISIÓN CHILENA DE DERECHOS HUMANOS (2020). La mirada de sus protagonistas. El Estallido Social y el Derecho de Libre Determinación. Los Derechos Humanos como horizonte común del movimiento social. Santiago: CCHDH.

COMISIÓN INTERAMERICANA DE DERECHOS HUMANOS (2019). "Informe visita preparatoria misión in loco Chile”. Disponible en https://www.oas.org/es/cidh/prensa/ comunicados/2019/312.asp

COMITÉ DE DERECHOS ECONÓMICOS, SOCIALES Y CULTURALES (2015). “Observaciones Finales sobre el cuatro Informe periódico de Chile". Disponible en https://acnudh. org/24619/

HUMAN RIGHTS WATCH (2019). "Informe Misión Observación Chile". Disponible en https://www.hrw.org/es/news/2019/11/26/chile-llamado-urgente-una-reforma-policial-traslas-protestas

INSTITUTO NACIONAL DE DERECHOS HUMANOS (2010). Informe Anual Situación de los Derechos Humanos en Chile. Santiago.

INSTITUTO NACIONAL DE DERECHOS HUMANOS, ARAUCANÍA (2020). Reporte interno, marzo del 2020. Temuco.

LE BONNIEC, F. (2014). "Las cárceles de la etnicidad: experiencias y prácticas de resistencia de los mapuche sometidos a la violencia política en la era del multiculturalismo (2000-2010)". Oñati SocioLegal Series, Vol. 4, No. 1.

LEPE-CARRIÓN, P. (2018). "Invención del sujeto intercultural: pensar «lo colonial» desde los umbrales de inteligibilidad del terror". Tabula Rasa, (29), 157-180. 
MARIMAN, P. et. al. (2004). "Epílogo".jEscucha winka! Cuatro ensayos de Historia Nacional Mapuche y un epílogo sobre el futuro. Santiago: Lom Ediciones.

NACIONES UNIDAS, CONSEJO DE DERECHOS HUMANOS, (2019) “Informe del Grupo de Trabajo sobre el Examen Periódico Universal Chile".

NACIONES UNIDAS (2011). Declaración sobre Educaición y Formación en Materia de Derechos Humanos.

NACIONES UNIDAS, OFICINA DEL ALTO COMISIONADO DE DERECHOS HUMANOS (2019) "Informe sobre la Misión a Chile". Disponible en https://acnudh.org/ equipoonu-derechoshumanos-finalizo-su-visita-a-chile/ NACIONES UNIDAS (1948). Declaración Universal de Derechos Humanos.

(1966). Pacto Internacional de Derechos, Económicos, Sociales y Culturales. PAIRICAN, F. (2014). Malon. La Rebelión del Movimiento Mapuche 1990-2013. Santiago: Editorial Pehuén.

SALAS, R. (2006). Ética intercultural. Ensayos de una ética discursiva para contextos culturales conflictivos. (Re) Lecturas del pensamiento latinoamericano. Quito: Ediciones Abya-Yala.

SALAZAR, C. (2020). "El lugar de la educación en la futura constitución". En: https:// surrealidad.cl/blog/2020/06/09/el-lugar-de-la-educacion-en-la-futura-constitucion/ SQUELLA, A. (2000). Introducción al Derecho. Santiago: Editorial Jurídica de Chile. TRICOT, T. (2017). "Movimiento mapuche, Política, Violencia Política, Contra-Violencia, Autonomía". Persona \& Sociedad, vol. XXXI, ㄲo2.

VARGAS, R. (2017) Pewmas / Sueños de Justicia y dirigentes mapuche versus Chile en la Corte Interamericana. Santiago de Chile: LOM Ediciones. 


\section{Cronología}

\begin{tabular}{|c|c|}
\hline Fecha & Acontecimiento \\
\hline $\begin{array}{l}\text { 04 de enero } \\
2019\end{array}$ & 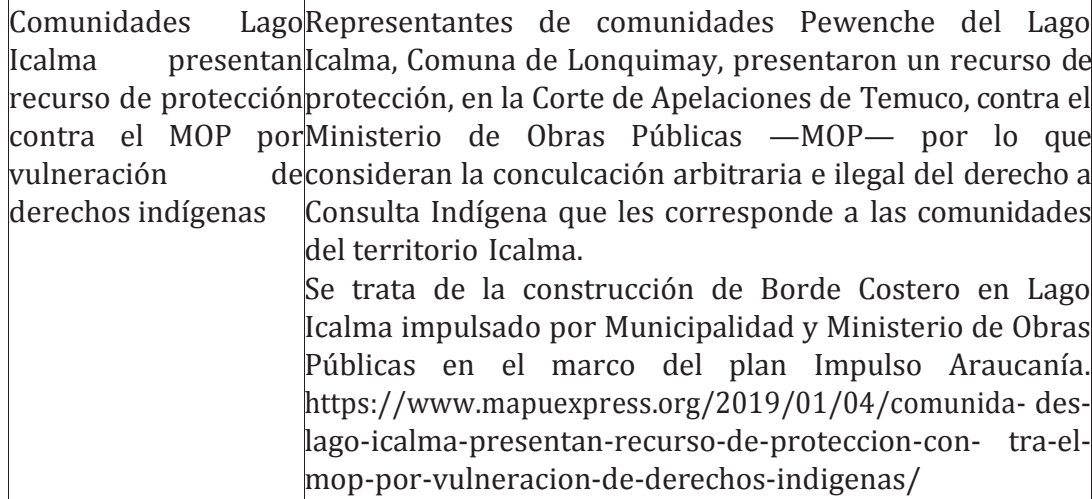 \\
\hline $\begin{array}{l}\text { 04 de enero } \\
\text { de } 2019\end{array}$ & \begin{tabular}{l|l} 
Conmemoración & En la región de La Araucanía, y en otras ciudades de Chile \\
asesinato & Matíasse realizan actos de conmemoración, marchas y otras \\
Catrileo & $\begin{array}{l}\text { manifestaciones para no olvidar los } 11 \text { años de su } \\
\text { asesinato efectuado por Carabineros de Chile. }\end{array}$
\end{tabular} \\
\hline
\end{tabular}

22 de eneroChile rinde el ExamenEl EPU es el examen en derechos humanos más completo de 2019 Periódico Universalque rinde un Estado, se realiza cada 4 años, y es (EPU) examinado por otros Estados parte de Naciones Unidas, quienes realizan recomendaciones, las cuales deben mostrar avance en los 4 años siguientes.

Se informó que el país recibió un total de 266 recomendaciones y Chile deberá dar a conocer su posición respecto a dichas recomendaciones a más tardar durante el $41^{\circ}$ periodo de sesiones del Consejo de Derechos Humanos, a celebrarse en junio de 2019. https://acnudh.org/examen-periodico-universal-adoptan-proyecto-de-informe-de-chile/

18 al 20 eneroParlamento de KozEl Parlamento de Koz koz, es una organización williche 2019 Koz activa, que promueve cambios estructurales de sociedad, buena convivencia entre los pueblos, participaciones, libertades y derechos colectivos. Rememora una actividad tradicional de diálogo.

https://www.mapuexpress.org/2019/01/09/proximo18-19-y-20-de-enero-autoconvocatoria-para-el-parlamento-mapuche-de-koz-koz/

25 de eneroProclamación añoPara el Pueblo Mapuche la revitalización lingüística ha sido de 2019 internacional de lasuna lucha constante, muchas veces de manera autolenguas indígenas. gestionada, sin aportes del Estado, por ello en el año de las lenguas se promovieron diversas instancias de tras- paso del idioma, cursos, seminarios, talleres, internados, los 


\begin{tabular}{|l|l|l|}
\hline & $\begin{array}{l}\text { cuales tuvieron una amplia demanda tanto por perso- nas } \\
\text { mapuche } \\
\text { https://es.unesco.org/news/presentacion-del-ano-inter- } \\
\text { nacional-lenguas-indigenas-2019 }\end{array}$ \\
\hline
\end{tabular}

31 de eneroAlegato de recurso deEl Plan Impulso consideraba el desarrollo de diversos de 2019 protección contraproyectos productivos, los cuales impactaban en recursos "Plan Impulsonaturales y prácticas culturales, lo cual no era aprobado Araucanía" ypor múltiples comunidades mapuche. Estas deciden "Acuerdo Nacionalinterponer un recurso de protección, que tiene por por La Paz Araucanía,objetivo principal exigir al estado de Chile que se respete y presentado poraplique el derecho a consulta, de acuerdo al estándar de Comunidades derecho internacional establecido por el Convenio $169 \mathrm{de}$ Mapuche la

https://www.mapuexpress.org/2019/01/29/comunicado-publico-este-jueves-organizaciones-mapuche-presentaran-recurso-de-proteccion-contra-plan-impulso-araucania-y-acuerdo-nacional-por-la-paz-en-la-araucania/

\begin{tabular}{|c|c|c|}
\hline $\begin{array}{l}15 \text { de febrero } \\
\text { de } 2019\end{array}$ & $\begin{array}{l}\text { Marcha por } \\
\text { revitalización } \\
\text { mapuzugun }\end{array}$ & $\begin{array}{l}\text { laComo todos los años en el marco de la conmemoración de } \\
\text { del día internacional de las lenguas originarias, se realiza er } \\
\text { Temuco una masiva marcha para exigir el pleno ejercicic } \\
\text { de los derechos lingüísticos. }\end{array}$ \\
\hline
\end{tabular}

17 de febrero Corte SupremaLa Corte Suprema emitió su fallo respecto del recurso de de 2019 ratifica condena anulidad presentado por la defensa de Facundo Jones Huala, Facundo Jones Huala lonko de la comunidad de Cushamen, ubicada en la Patagonia argentina. La autoridad mapuche fue condenada en diciembre de 2018 por el Tribunal Oral en lo Penal de Valdivia, acusado de ser el autor del incendio en el fundo Pisu Pisué, comuna de Río Bueno, en el año 2013. El veredicto unánime de los ministros, ratificó los nueve años de cárcel que actualmente cumple Jones Huala en la cárcel de Temuco.

19 de febrero Alvaro Millalen seSe suma a la huelga de hambre líquida que llevaron a cabo de 2019 suma a huelga deFacundo Jones Huala, Jorge Cayupan y José Cáceres para

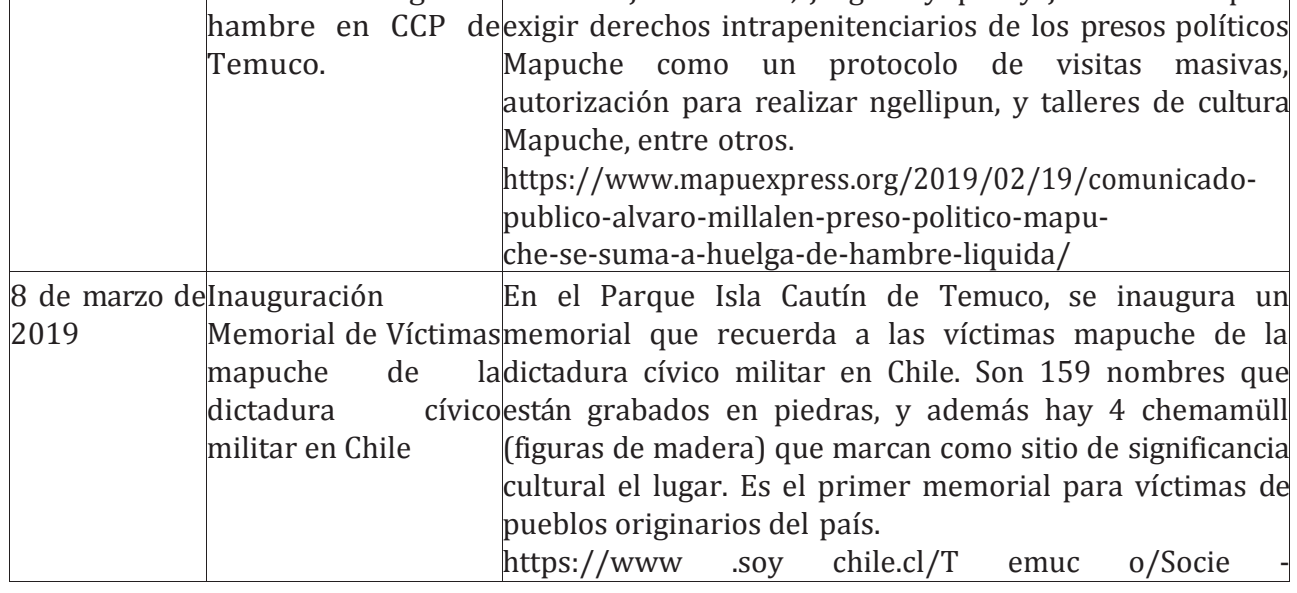


Capitulo 4. Página 19

dad/2019/03/08/584799/En-Isla-Cautin-en-Temu-

$\mathrm{co}-$

inauguraron-memorial-por-las-159-mapuches-victi-

mas-en-dictadura.aspx

08 de marzo Conmemoración 8M En diversas ciudades del país, se conmemora el día de 2019

Internacional de la Mujer, desarrollándose múltiples actividades por la igualdad de derechos y dignidad de las mujeres. En Santiago se desarrolla una marcha multitudinaria, denominada "la movilización más grande de la historia". https://www.eldesc oncierto.cl/2019/03/09/ la-movilizacion-mas-grande-de-la-historia-tie- ne-rostrode-mujer-coordinadora-8m-realiza-ba- lance-de-huelgafeminista-y-cifra-en-800-mil-muje- res-movilizadas-anivel-nacional/

22 de abril deMovilización En el marco internacional del Día de la Tierra, se 2019 Plurinacional por eldesarrollan múltiples actividades formativas, de denuncias Agua y los Territorios y de autogestión desde Calama a Chilóe, por la defensa de los territorios.

https://www.mapuexpr es s.or g/2019/04/21/

in i c i a - la - 7 o-movili z a c i o n - plurina ci o nal-por-el-agua-y-los-territorios/

06 de abril Misión deINDH realiza Misión de Observación en la comuna de Alto de 2019 Observación en AltoBiobío, región del Biobío, constatando una serie de Biobio vulneraciones a los derechos humanos de las comunidades pewenche.

https://radio.uchile.cl/2019/04/06/resultado-de-estudio-del- indh- comunidades- indigenas- del- al- to-biobio-viven-desplazadas-y-sin-agua/

\begin{tabular}{|l|lr}
\hline Abril a junio & $\begin{array}{l}\text { Desarrollo } \\
\text { Indígena } \\
\text { modificación } \\
\text { Indígena }\end{array}$ & $\begin{array}{r}\text { ConsultaEntre los meses de abril a junio } 2019 \text { se desarrolla el } \\
\text { porproceso de Consulta Indígena, desarrollada por el } \\
\text { Ley }\end{array}$ \\
& $\begin{array}{l}\text { Ministerio de Desarrollo Social y Familia, con la finalidad } \\
\text { de modificar la Ley Indígena. } \\
\text { Esta consulta tuvo un amplio rechazo a nivel nacional. El } \\
\text { proceso se suspende al finalizar su primera etapa, yluego } \\
\text { en noviembre 2019, se cancela definitivamente el proceso. } \\
\text { https://radio.uchile.cl/2019/07/26/consulta-indi-gena- } \\
\text { gobierno-evalua-suspender-de-forma-defini-tiva-el- } \\
\text { proceso/https://radio.uchile.cl/2019/07/26/consulta- } \\
\text { indigena-gobierno-evalua-suspender-de-for-ma-definitiva- } \\
\text { el-proceso/ } \\
\text { https://www.adnradio.cl/nacional/2019/11/13/ministerio- } \\
\text { de-desarrollo-social-puso-termino-a-consulta-indi- } \\
\text { gena-3978640.html }\end{array}$ \\
\hline
\end{tabular}

29 de abril dePremio

2019 Lonko

Curamil
Goldman aEl Premio Medioambiental Goldman "honra los logros y el Albertoliderazgo de los activistas medioambientales comunitarios de todo el mundo y nos inspira a todos a tomar medidas para proteger nuestro planeta".

Uno de los seis reconocimientos recae en el Lonko Alberto Curamil, en su calidad de defensor de su territorio y de 
15 de mayo deComunidad mapucheComunidad Juan Paillalef, de Cunco, Araucanía participa 2019 asiste a audiencia deen sesión de la CIDH

la Comisiónhttps://www.mapuexpress.org/2019/05/15/comunidad-

Interamericana dejuan-paillalef-participa-del-172-periodo-de-se- siones-deDerechos Humanosla-cidh-en-jamaika/

(CIDH).

07 de mayo Conformación de Se formaliza el trabajo que se desarrolla en pos de la de 2019 Mesa Regional deinfancia mapuche, por diversas instituciones públicas y Infancia Mapuche enprivadas en la Región de La Araucanía. Temuco. $\quad$ https://www.indh.cl/se-conforma-en-la-araucania-me- saintersectorial-para-la-proteccion-de-los-dere- chos-deninos-as-mapuche/

05 de junio Presentan Recurso dela presentación se realiza dado los hostigamientos de 2019 amparo a favor depoliciales vividos luego de su presentación a favor de vocera de la Red porniños/ as mapuche en la Comisión de la Cámara de la Defensa de laDiputados que investiga el homicidio de Camilo Infancia Mapuche Catrillanca.

https://www.mapuexpr es s.or g/2019/06/06/ recurso-de-amparo-a-favor-de-onesima-lienqueo/

12 de junioComisión deEn un hecho histórico el Congreso recibe a una delegación 2019 Derechos Humanosde más de 200 representantes del Pueblo Mapuche, de la Cámara desolicitaron la desmilitarización de la zona y el fin del Diputados/as recibeproceso de la Consulta Indígena. al Pueblo Mapuche https://www.camara.cl/prensa/sala_de_prensa_detalle. aspx?prmid $=137279$

19 de junio deGobierno Ingresa aEl proyecto de Ley es rechazado por múltiples actores 2019 Cámara de Diputados,(pueblos indígenas, colegio de arqueólogos, artistas, entre Ley de Patrimoniootros). Los principales reparos son la nula participación de Cultural, sin Consultaagentes expertos, la no realización de la Consulta Indígena, Indígena ya que existe plena afectación de sus derechos y donde se promovería un "despojo cultural". https://www.camara.cl/prensa/sala_de_prensa_detalle. aspx?prmid $=137320$

https://www.biobiochile.cl/noticias/artes-y-cultura/actualidad-cultural/2019/08/12/frente-por-una-ley-de-patrimonio-hace-durisima- critica-al-pr oyec to-de-ley-del-gobierno.shtml

07 de agosto Senado aprueba en Es una modificación que considera entre otros puntos el de 2019 general Ley Cortafortalecimiento de técnicas investigativas, como la antiterrorista inclusión de agentes encubiertos, interceptación de comunicaciones, agentes reveladores, entre otros.

Estas modificaciones están reñidas con los estándares internacionales de derechos humanos.

https://www.senado.cl/senado-aprueba-en-general-ley-corta-antiterrorista/senado/2019-08-07/170817. html 


\section{Capitulo 4. Página 21}

30 de agosto Conmemoración del A nivel nacional e internacional se desarrollan actividades de 2019 Día Internacional delde conmemoración a las víctimas de desaparecidas en Detenido/a manos de agentes del Estado.

Desaparecido/a

05 deConmemoración DíaEs una conmemoración que cada año se hace más visible septiembre deInternacional Mujeren Chile y en países vecinos. Para las organizaciones de 2019 Indígena mujeres mapuche es una instancia para recobrar la dignidad.

https://www.ufro.cl/index.php/noticias/12-destacadas/2995-palabras-saludo-rector-dia-de-la-mujer-ind\%C3\%ADgena

18 de octubreEstallido Social enA nivel nacional comienzan una serie de manifestaciones gatilladas por un alza en la movilización pública, pero que tiene sus raíces profundas en la desigualdad instalada por el modelo neoliberal. Las movilizaciones se expresan de manera intensa desde el 18 de octubre hasta fines de diciembre de 2019, dejando personas muertas y miles de víctimas lesionadas por agentes del Estado.

Dada la gravedad de los hechos, delegaciones de derechos humanos, tanto del sistema universal como del interamericano se hacen presente para observar la crisis social y entregar recomendaciones al Estado de Chile. https://www.lemondediplomatique.cl/el-estallido-social-en-chile-por-oscar-torres.html

9 deMisión Internacio-Diversos observadores/as de derechos humanos visitan la noviembre denal de DD.HH. visitaRegión de La Araucanía, para recabar relatos y 2019 La Araucanía antecedentes en el contexto de la crisis social, desatada desde el 18 de octubre 2019, es la primera de varias delegaciones de DD.HH. que visitaron la Región. https://www.biobiochile.cl/noticias/nacional/re-gion-dela-araucania/2019/11/09/observadores-internacionales-de-ddhh-llegan-a-la-araucania-liderados-por-las-madres-de-plaza-de-mayo.shtml

14 deConmemoración En diversas ciudades del país se realizaron actividades noviembre deasesinato Camiloconmemorativas del primer aniversario del asesinato de $2019 \quad$ Catrillanca Camilo Catrillanca, a manos de Carabineros de Chile. https://www.mapuexpress.org/2019/11/14/val- paraisoveinte-mil-personas-recuerdan-y-rin- den-homenajes-a camilo-catrillanca-al-cumplirse-un-ano-de-ser-asesinado-por-agentes-del-estado/

\begin{tabular}{|c|c|}
\hline Noviembre & 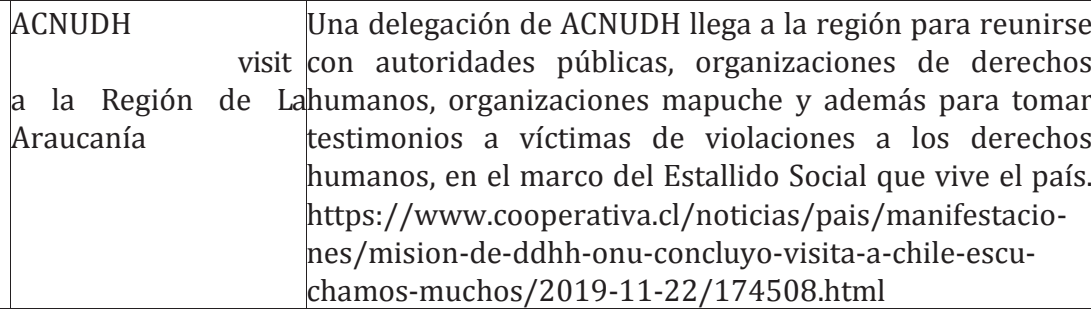 \\
\hline
\end{tabular}




\section{Capitulo 4. Página 22}

\begin{tabular}{|c|c|}
\hline $\begin{array}{l}21 \\
\text { noviembre } \\
2019\end{array}$ & $\begin{array}{l}\text { deAmnistía } \\
\begin{array}{l}\text { deInternacional da aseguridad chilenas es clara: lesionar a quienes se } \\
\text { conocer informemanifiestan para desincentivar la protesta, incluso } \\
\text { sobre Estallidollegando al ex- tremo de usar la tortura y violencia sexual } \\
\text { Social en Chile }\end{array} \\
\begin{array}{l}\text { en contra de manifestantes" } \\
\text { https://amnistia.cl/noticia/chile-politica-delibera-da- } \\
\text { para-danar-a-manifestantes-apunta-a-responsabili- } \\
\text { dad-de-mando/ }\end{array}\end{array}$ \\
\hline $\begin{array}{l}25 \\
\text { novien } \\
2019\end{array}$ & $\begin{array}{l}\text { deSe suspende juicioEl Tribunal Oral en lo Penal de Angol acogió la solicitud de } \\
\text { deoral por asesinato dedefensa del ex jefe de FFEE de Carabineros de La } \\
\text { Camilo CatrillancaAraucanía, quien solicitó aplazamiento por razones de } \\
\begin{array}{ll}\text { Marín } & \text { salud, quedando agendado para el } 2 \text { de marzo de } 2020 . \\
& \text { https://radio.uchile.cl/2019/11/25/para-marzo-jui- } \\
& \text { cio-oral-en-caso-catrillanca-se-suspende-hasta-2020/ }\end{array}\end{array}$ \\
\hline $\begin{array}{l}06 \\
\text { diciembre } \\
2019\end{array}$ & $\begin{array}{l}\text { deCIDH condena el usoEl informe de la CIDH constata una serie de violaciones a } \\
\text { deexcesivo de la fuerzalos derechos humanos, manifestando su alarma por los } \\
\text { en el contexto de lasnumerosos casos de lesiones oculares, torturas y tratos } \\
\text { protestas sociales encrueles, violencia sexual y detenciones arbitrarias. } \\
\begin{array}{ll}\text { Chile } & \text { http://www.oas.org/es/cidh/prensa/comunicados/2019/ } \\
\text { 317.asp }\end{array}\end{array}$ \\
\hline
\end{tabular}

